\title{
Host Immune Response Driving SARS-CoV-2 Evolution
}

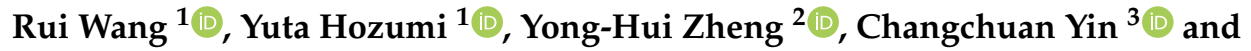 \\ Guo-Wei Wei $1,4,5, *$ (D) \\ 1 Department of Mathematics, Michigan State University, East Lansing, MI 48824, USA; \\ wangru25@msu.edu (R.W.); hozumiyu@msu.edu (Y.H.) \\ 2 Department of Microbiology and Molecular Genetics, Michigan State University, \\ East Lansing, MI 48824, USA; zhengyo@msu.edu \\ 3 Department of Mathematics, Statistics, and Computer Science, University of Illinois at Chicago, \\ Chicago, IL 60607, USA; cyin1@uic.edu \\ 4 Department of Biochemistry and Molecular Biology, Michigan State University, East Lansing, MI 48824, USA \\ 5 Department of Electrical and Computer Engineering, Michigan State University, \\ East Lansing, MI 48824, USA \\ * Correspondence: weig@msu.edu
}

Received: 17 August 2020; Accepted: 21 September 2020; Published: 27 September 2020

check for updates

\begin{abstract}
The transmission and evolution of severe acute respiratory syndrome coronavirus 2 (SARS-CoV-2) are of paramount importance in controlling and combating the coronavirus disease 2019 (COVID-19) pandemic. Currently, over 15,000 SARS-CoV-2 single mutations have been recorded, which have a great impact on the development of diagnostics, vaccines, antibody therapies, and drugs. However, little is known about SARS-CoV-2's evolutionary characteristics and general trend. In this work, we present a comprehensive genotyping analysis of existing SARS-CoV-2 mutations. We reveal that host immune response via APOBEC and ADAR gene editing gives rise to near $65 \%$ of recorded mutations. Additionally, we show that children under age five and the elderly may be at high risk from COVID-19 because of their overreaction to the viral infection. Moreover, we uncover that populations of Oceania and Africa react significantly more intensively to SARS-CoV-2 infection than those of Europe and Asia, which may explain why African Americans were shown to be at increased risk of dying from COVID-19, in addition to their high risk of COVID-19 infection caused by systemic health and social inequities. Finally, our study indicates that for two viral genome sequences of the same origin, their evolution order may be determined from the ratio of mutation type, $\mathrm{C}>\mathrm{T}$ over $\mathrm{T}>\mathrm{C}$.
\end{abstract}

Keywords: SARS-CoV-2; COVID-19; APOBEC; ADAR; gene editing

\section{Introduction}

The ongoing outbreak of coronavirus disease 2019 (COVID-19), caused by severe acute respiratory syndrome coronavirus 2 (SARS-CoV-2), has led to tremendous human mortality and economic hardship. As of 31 July 2020, over 17,106,007 confirmed COVID-19 cases have been reported worldwide and 668,910 deaths have occurred from the disease [1]. To mitigate this devastating pandemic, we have to control its spread by sufficient testing, social distancing, contact tracking, and developing effective diagnosis tools, efficacious antiviral drugs, antibody therapies, and preventive vaccines.

SARS-CoV-2 is a positive-sense, single-strand RNA virus that belongs to the beta coronavirus genus [2]. It has a genome size of $29.82 \mathrm{~kb}$, which encodes multiple non-structural and structural proteins. The ORF1ab encode non-structural proteins for RNA replication and transcription. The downstream regions of the genome encode structural proteins, including the spike (S) protein, 
the nucleocapsid $(\mathrm{N})$ protein, the envelope $(\mathrm{E})$ protein, and the membrane $(\mathrm{M})$ protein. All of the four major structural proteins are required to produce a structurally complete viral particle. The $S$ protein mediates viral attachment to the host angiotensin-converting enzyme 2 (ACE2) receptor and subsequent fusion between the viral and host cell membranes aided by transmembrane serine protease 2 (TMPRSS2) to allow the entry of viruses into the host cell [3-5]. The nucleocapsid (N) protein, one of the most abundant viral proteins, binds to the RNA genome and is involved in replication processes, assembly, and host cellular response during viral infection [6].

Mutagenesis is a basic biological process that changes the genetic information of organisms. As a primary source of many kinds of cancers and heritable diseases, mutagenesis may be fearful but is a driving force for natural evolution $[7,8]$. Although viruses are not organisms per se, they are at the edge of life. Our real-time interactive SARS-CoV-2 Mutation Tracker (https://users.math. msu.edu/users/weig/SARS-CoV-2_Mutation_Tracker.html) shows that over 15,000 mutations have occurred on SARS-CoV-2 [9]. More than 1700 mutations on the $S$ protein gene have a significant impact on SARS-CoV-2 infectivity [10-12]. These mutations should be put into the perspective that COVID-19 has globally spread. The geographical and demographical diversity of the viral transmission and exogenous and endogenous genotoxins exposure have stimulated SARS-CoV-2 mutations. If we consider the average number of mutations per genome, SARS-CoV-2 is mutating slower than other viruses, such as the flu and common cold viruses [13,14]. This is because SARS-CoV-2 belongs to the coronaviridae family and the Nidovirales order, which has a genetic proofreading mechanism in its replication achieved by an enzyme called non-structure protein 14 (NSP14) in synergy with NSP12, i.e., RNA-dependent RNA polymerase (RdRp) [15,16]. As a result, SARS-CoV-2 has a relatively high fidelity in its transcription and replication processes. In general, Coronavirus mutations are created from three major sources, namely, random errors in replication, such as genetic drift and spontaneous genotoxins, viral replication proofreading and defective repair mechanisms, and host immune responses, such as gene editing [11,17]. Genotyping tracks mutations, overpopulation, space, and time, while also providing a method to understand the molecular mechanism of SARS-CoV-2 proteins, protein-protein interactions, and their synergy with host cell proteins, enzymes, and signaling pathways.

The studies of SARS-CoV genomes have, to date, predominantly focused on understanding genome mutation variants, implications in virus transmissions $[18,19]$, and ramifications on the development of diagnostics [9,20], vaccines [21], antibodies [22], and drugs [21]. Although it is difficult to determine the detailed mechanism of every specific mutation, early work on a few initial SARS-CoV-2 strains in Wuhan, China, revealed that hypermutations $C>T$ are most likely resulted from the APOBEC (apolipoprotein B mRNA editing enzyme, catalytic polypeptide-like) deamination in RNA editing [23]. Simmonds noted that a large proportion of $C>T$ mutations in a host APOBEC-like context in the initial months of the pandemic provide evidence for a potent host-driven antiviral editing mechanism against SARS-CoV-2 [24]. An accumulation of $\mathrm{C}>\mathrm{T}$ mutations in SARS-CoV-2 variants was also reported in [25]. In the standard genetic code, all three stop codons, TAA, TAG, and TGA, involve $\mathrm{T}$ but not $\mathrm{C}$. Therefore, the gene-editing imposed $\mathrm{C}>\mathrm{T}$ mutations will have a high possibility of terminating the translation of viral proteins, which undermines viral functions and survivability. To be noted, as stated in [25], the $C>$ T mutation can increase the frequency of codons for hydrophobic amino acids, which may have an effect on the properties of SARS-CoV-2 proteins. The spontaneous $\mathrm{C}>\mathrm{T}$ transitions and APOBEC deamination can lead to cancer in humans. There are two well-known deaminase RNA editing mechanisms in human cells: the APOBEC [26] and the adenosine deaminases acting on RNA (ADAR) [27]. The APOBEC enzymes deaminate cytosines into uracils $(\mathrm{C}>\mathrm{U}$ ) on single-stranded nucleic acids (ssDNA or ssRNA). It is well established that the human genome encodes activation-induced cytidine deaminases (AIDs) and several homologous APOBEC cytidine deaminases that function in innate immunity as well as in RNA editing [28,29]. In both innate and adaptive immunity, AID and APOBEC cytidine deaminases modulate immune responses by mutating specific nucleic acid sequences of hosts and pathogens. The ADAR enzymes 
deaminate adenines into inosines (A-to-I) and result in A > G mutation. The significance of A-to-I editing is its abundance in both host and viral RNAs. ADAR enzymes play important roles during viral infections. They can have either a proviral or an antiviral consequence, depending on the virus-host combination $[30,31]$.

The APOBEC family proteins play critical functional roles within the adaptive and innate immune system, which is involved soon after the infection [32]. Therefore, the higher ratio of $\mathrm{C}>\mathrm{T}$ mutations may indicate the strong capacity of the host immune system. However, a strong immune response is a double-edged sword. On the one hand, it may help host cells to defeat the virus more efficiently. On the other hand, it can result in a "cytokine storm", which is a key cause of the death of COVID-19 patients by the exponential growth of inflammation and organ damage [33].

In this work, we analyze a large volume of single-nucleotide polymorphisms (SNPs) found in 33,693 complete SARS-CoV-2 genome isolates globally. By analyzing the distribution of 12 SNP types, we notice that the ratio of $\mathrm{C}>\mathrm{T}$ mutations is predominately higher than that of the other types of mutations, indicating that hypermutation $\mathrm{C}>\mathrm{T}$ may result from extensive host RNA editing, i.e., the APOBEC deamination. Additionally, we investigate the distribution of 12 SNP types in different age groups, gender groups, and geographic locations to understand whether these hypermutations have a age/gender/demographic preference. Moreover, we provide deep insights into the mutation motif and hot-spot patterns from 13,833 single mutations decoded from 33,693 complete SARS-CoV-2 genome sequences, revealing mutational signatures and preferred genetic environments. Finally, we hypothesize that virus genomes evolve through host innate immune response imposed gene editing, i.e., $\mathrm{C}>\mathrm{T}$, and virus protective mechanism-installed defective revisionary mutations, $\mathrm{T}>\mathrm{C}$. As a result, both $\mathrm{C}>\mathrm{T}$ and $\mathrm{T}>\mathrm{C}$ mutation ratios are usually high. We show that the ratio of $\mathrm{C}>\mathrm{T}$ to $\mathrm{T}>\mathrm{C}$ mutations is higher than the unity in the forward viral evolution, which suggests the master and slave relationship between host gene editing and virus protective mechanism. Therefore, we propose that the $\mathrm{C}>\mathrm{T}$ to $\mathrm{T}>\mathrm{C}$ ratio being higher than the unity $(>1)$ is an indication of the forward viral evolution direction.

\section{Methods and Materials}

\subsection{SNP Genotyping}

Here, 33,693 complete genomes of the SARS-CoV-2 strains of the globe were retrieved from the GISAID database [34] on 31 July 2020. Only the complete genomes of high-coverage that have no stretches of 'NNNNN' were included in the dataset. The complete genome sequences were aligned with the reference genome of SARS-CoV-2 by the multiple sequence alignment (MSA) tool Clustal Omega using the default parameters [35]. The SNP mutations were retrieved from the aligned genomes according to the reference SARS-CoV-2 genome that is derived from the human coronavirus Wuhan-1 isolate (GenBank access number: NC_045512.2) [2]. The SNP profile, including nucleotide changes and the corresponding positions in a genome, can be considered as the genotype of the virus.

\subsection{Multiple Sequence Alignment}

As mentioned above, Clustal Omega is used to do multiple sequence alignments. The basic idea of the Clustal Omega is to produce a pairwise alignment using the $k$-tuple method. Given two sequences, $S_{1}$ and $S_{2}$, a $k$-tuple match is defined as j-letters that match in $S_{1}$ and $S_{2}$

$$
\left\{S_{1}(i), S_{1}(i+1), \ldots, S_{1}(i+k-1)\right\}=\left\{S_{2}(j), S_{2}(j+1), \ldots, S_{2}(j+k-1)\right\}
$$

where $i, j$ are positions of the sequence, such as DNA, RNA and amino acid sequences. The distance between the two sequences is then defined as

$$
d_{i}\left(S_{1}, S_{2}\right)=1-\frac{C_{i}\left(S_{1}, S_{2}\right)}{C_{t}}
$$


where $C_{i}\left(S_{1}, S_{2}\right)$ is the number of $k$-tuple matches between $S_{1}$ and $S_{2}$ and $C_{t}$ is the sum of all paired residue of $S_{1}$ and $S_{2}$ (i.e., the total number of matches). A dot matrix between $S_{1}$ and $S_{2}$ can be computed by matching $k$-tuples between $S_{1}$ and $S_{2}$. The diagonal element above a certain threshold is called the "window space". By utilizing the Needleman-Wunsch method restricted to the "window space", we can find an alignment, which has the highest score that can be calculated from the Needleman-Wunsch method [35].

To find the optimal alignment, other methods, such as the mBed method and the UPGMA method, can also be employed [36,37]. As an advanced MSA tool, the Clustal Omega guarantees high accuracy and is time-efficient.

\subsection{SNP Analysis}

The Cluster Omega is employed to carry out the multiple sequence alignment. The genomic analytics are performed using computer programs in Python and Biopython libraries [38].

\subsection{Data Availability}

The nucleotide sequences of the SARS-CoV-2 genomes used in this analysis are available, upon free registration, from the GISAID database (https://www.gisaid.org/). The SNP IDs and the acknowledgments of the SARS-COV-2 genomes are given in the Supporting Information.

\section{Results}

To reveal that $\mathrm{C}>\mathrm{T}$ and $\mathrm{A}>\mathrm{G}$ mutations are driven by RNA-APOBEC and RNA-ADAR editing, we first analyzed 33,693 complete SARS-CoV-2 genome sequences, and a total of 13,833 single mutations were found as of 31 July 2020 . To be noted, 13,833 single mutations were unique mutations, i.e., the same mutation appearing in different SARS-CoV-2 isolates is only counted once. If we count the same mutation in different SARS-CoV-2 isolates repeatedly according to their frequency, then all of the mutations that are detected in the 33,693 complete SARS-CoV-2 genome sequences are called non-unique mutations. With the reference sequence of SARS-CoV-2 genome collected on 5 January 2020 [2], we calculated the proportion of 12 SNP types (i.e., A $>$ T, A $>C, A>G, T>A$, $\mathrm{T}>\mathrm{C}, \mathrm{T}>\mathrm{G}, \mathrm{C}>\mathrm{T}, \mathrm{C}>\mathrm{A}, \mathrm{C}>\mathrm{G}, \mathrm{G}>\mathrm{T}, \mathrm{G}>\mathrm{C}, \mathrm{G}>\mathrm{A}$ ) worldwide. The unusually high ratios of $\mathrm{C}>\mathrm{T}$ and $\mathrm{A}>\mathrm{G}$ mutations indicate that RNA-APOBEC editing and RNA-ADAR editing are involved in the host immune response to SARS-CoV-2 infection [28,29]. Additionally, to understand gene-editing preference, we investigated the distribution of 12 SNP types of mutations in different countries/regions, age groups, and gender groups. Furthermore, we decoded mutation motifs from the 2-mer and 3-mer sequence contexts to survey the hot-spot patterns and mutational signatures driven by gene-editing. Moreover, we analyzed the proportion of 12 SNP types among SARS-CoV, Bat-SL-BM48-31, Bat-SL-CoVZC45, Bat-SL-RaTG13, and SARS-CoV-2. We discovered that the viral evolution order can be determined by the ratios of $C>T / T>C$. These results are presented in following subsections.

\subsection{Host Immune Response to SARS-CoV-2 Infection with Gene Editing}

\subsubsection{Global Analysis}

Table 1 illustrates the proportion of 12 SNP types of SARS-CoV-2 (i.e., A $>$ T, A $>C, A>G$, $\mathrm{T}>\mathrm{A}, \mathrm{T}>\mathrm{C}, \mathrm{T}>\mathrm{G}, \mathrm{C}>\mathrm{T}, \mathrm{C}>\mathrm{A}, \mathrm{C}>\mathrm{G}, \mathrm{G}>\mathrm{T}, \mathrm{G}>\mathrm{C}, \mathrm{G}>\mathrm{A}$ ) in the global. Here we only consider the unique SNPs. 
Table 1. The distribution of 12 SNP types among unique mutations in the SARS-CoV-2 genome isolates worldwide. The unique SNP mutations are considered in the calculation, i.e., the same type of mutation in different genome isolates is only counted once.

\begin{tabular}{cllcll}
\hline SNP Type & Mutation Type & Ratio & SNP Type & Mutation Type & Ratio \\
\hline A $>$ T & Transversion & $4.44 \%$ & C $>$ T & Transition & $24.06 \%$ \\
A $>$ C & Transversion & $3.75 \%$ & C $>$ A & Transversion & $4.00 \%$ \\
A $>$ G & Transition & $14.87 \%$ & C $>$ G & Transversion & $1.25 \%$ \\
T $>$ A & Transversion & $3.43 \%$ & G $>$ T & Transversion & $13.33 \%$ \\
T $>$ C & Transition & $14.53 \%$ & G $>$ C & Transversion & $2.36 \%$ \\
T $>$ G & Transversion & $2.80 \%$ & G $>$ A & Transition & $11.17 \%$ \\
\hline
\end{tabular}

First, it can be seen that not all SARS-CoV-2 mutations are created equal. Mutation $\mathrm{C}>\mathrm{G}$ only accounts for $1.25 \%$. A few other mutation types, $\mathrm{G}>\mathrm{C}, \mathrm{T}>\mathrm{G}, \mathrm{T}>\mathrm{A}$, and $\mathrm{A}>\mathrm{C}$, are not frequent either. If mutations are random, each mutation should have a ratio of $8.3 \%$ on average. It can be seen that $\mathrm{C}>\mathrm{T}$ owns the largest proportion $(24.06 \%)$, which is much higher than the average ratio. Applying the Z-test, the $p$-value is $2.74 \times 10^{-274}$, which means our deduction is of statistical significance. Therefore, the hypermutation $C>T$ must be driven by additional mechanisms. It is known that host RNA-APOBEC editing leads to excessive $\mathrm{C}>\mathrm{T}$ transitions.

Moreover, the second most frequent mutation type is A $>$ G transition. Its A $>$ G ratio of $14.87 \%$ is much higher than the average ratio of $8.3 \%$, and the $p$-value $7.9 \times 10^{-64}$ from the Z-test implies that our deduction passes the hypothesis test. Therefore, RNA-ADAR editing is also involved in the host immune response. Although the high ratios of $C>T$ and $A>G$ reveal that the immune system is combating SARS-CoV-2 by two deaminase RNA editing mechanisms, the relatively high ratios of the reversed mutations $\mathrm{T}>\mathrm{C}$ and $\mathrm{G}>\mathrm{A}$ also indicate that SARS-CoV-2 fights the gene editing using its defective proofreading and repairing mechanisms.

Finally, it is well-known that mutations can be classified into four transition types (i.e., A $>$ G, $\mathrm{G}>\mathrm{A}, \mathrm{C}>\mathrm{T}$, and $\mathrm{T}>\mathrm{C}$ ) and eight transversion types. Table 1 shows that all transition types have relatively high ratios, whereas all transversion types, except for $\mathrm{G}>\mathrm{T}$, have relatively low ratios. This is due to the fact that it is easier to substitute a single-ring nucleotide structure for another single-ring nucleotide structure than to substitute a double-ring nucleotide for a single-ring nucleotide. Additionally, transitions are more likely to result in silent mutations. Therefore, transversions can be more destructive to viral genomes.

\subsubsection{Age Analysis}

Figure 1 illustrates the distribution of 12 SNP types among unique SNPs in SASR-CoV-2 genome isolates from different age groups. In general, with the increase in age, the ratio of $C>T$ gradually increased. Here, $42.1 \% \mathrm{C}>\mathrm{T}$ mutations were detected in patients who are older than 90 years old, indicating that gene-editing is more active in elderly patients than young patients. We applied the Z-test to the data of patients older than 90 years old and patients in other age groups, and all the resulting $p$-values were less than 0.05 . Therefore, our hypothesis is statistically significant. However, the severe COVID-19 cases may be due to the immune systems' heightened response. When SARS-CoV-2 infects a host cell, a set of proteins called cytokines will be released from a broad range of cells (mainly immune cells). Cytokines are involved in the immune response to produce more immune cells and recruit them to the sites of inflammation in order to fight against the viral infection. In turn, more cytokines can be released from the immune cells. This positive feedback loop will result in a "cytokine storm", which can beget the exponential growth of inflammation, trigger apoptosis, and lead to organ damage [33]. Therefore, we hypothesize that if the immune system overreacts to the invading pathogens, it is more likely to cause the cytokine storm and aggravate the condition of COVID-19 patients. It can be seen in Figure 1, where patients who are older than 80 years old have more $\mathrm{C}>\mathrm{T}$ mutations compared to other age groups. This result reveals that APOBEC3 gene editing is more active 
with older people. Consequently, the cytokine storm may happen more frequently in older people than it does in younger people. This might be one of the main causes of the high COVID-19 fatality for the elderly. Age-related mutagenesis, i.e., $\mathrm{C}>\mathrm{T}$ transition, is known to cause more cancer diagnostics in the elderly [39].
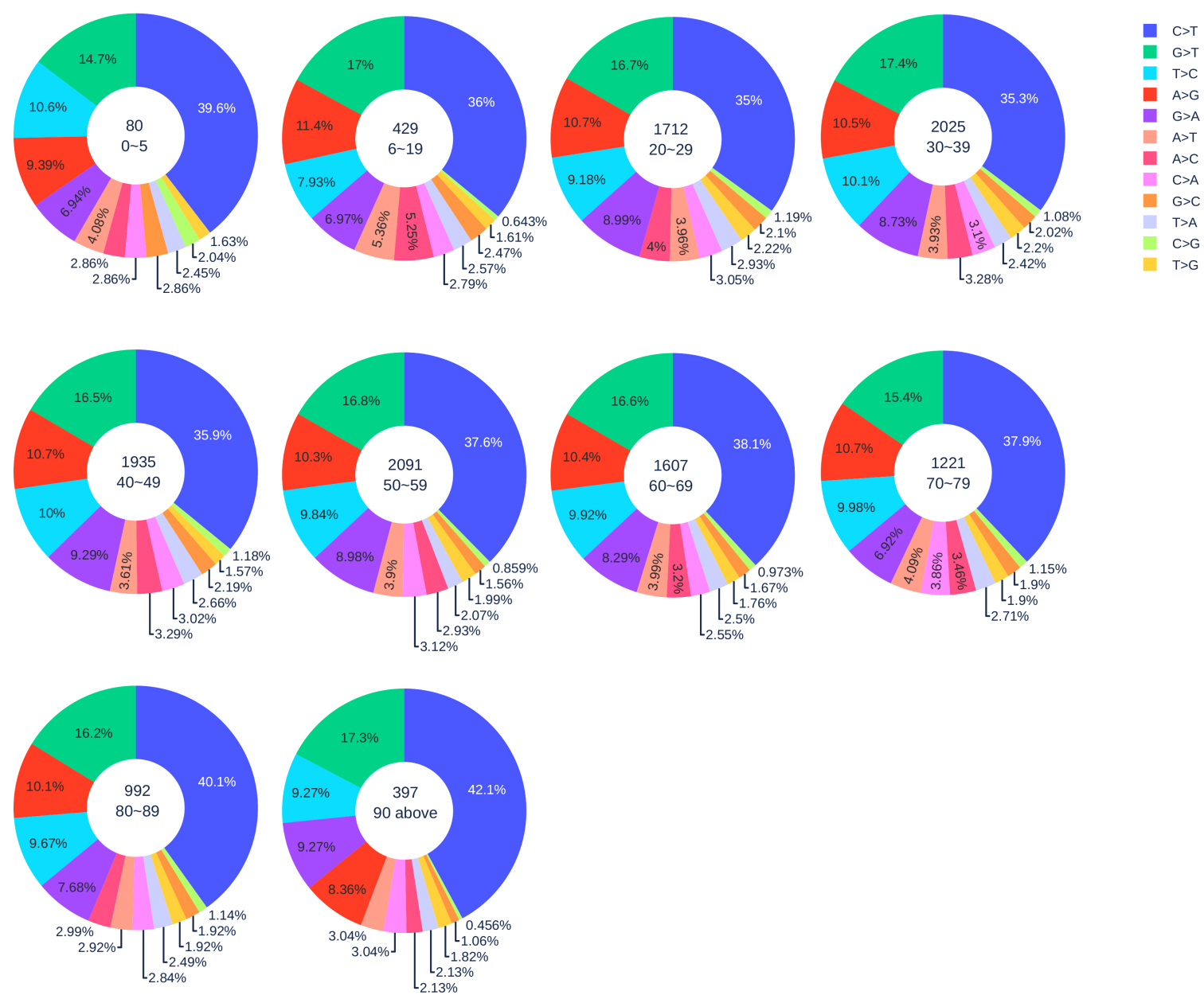

Figure 1. The distribution of 12 SNP types among unique mutations in the SARS-CoV-2 genome isolates from different age groups. The text inside each circle represents the total number of records that have age information for different age groups.

Notably, the SARS-CoV-2 samples from children under five years old have a relatively high ratio of C $>$ T mutations (39.6\%). The $p$-value from the Z-test is less than 0.05 , which also implies the statistical significance of a relatively high ratio of $C>T$ in patients under five years old. Moreover, the reversed mutation type $\mathrm{T}>\mathrm{C}$ for samples from children under five years old and adults older than 90 years old has the third-largest ratio. In other age groups, $\mathrm{T}>\mathrm{C}$ has the fourth-largest ratio. As demonstrated before, the reversed mutation $\mathrm{T}>\mathrm{C}$ may reveal that SARS-CoV-2 is capable of fighting back against the host immune system. Therefore, we deduce that SARS-CoV-2 will fiercely counter-attack the immune system in children under five and adults older than 90 .

Our result reveals that the immune systems of children under five years old are less well-developed and weaker than those of adults. They have to fight harder when SARS-CoV-2 infects. This result suggests that children under five are at risk of COVID-19. However, the long-term health consequence of young children's unusual response to SARS-CoV-2 infection remains to be further studied. 


\subsubsection{Gender Analysis}

Figure 2 shows the distribution of 12 SNP types in SARS-CoV-2 genome isolates globally from two gender groups. The ratio of $\mathrm{C}>\mathrm{T}$ mutations in females is slightly higher in males. We also apply a simple Z-test, and the $p$-value is 0.0302 , which is smaller than the significance level 0.05 . Therefore, the slightly higher $\mathrm{C}>\mathrm{T}$ ratios in females matches the finding that women have a stronger immune response than men $[40,41]$. Moreover, Figures 3 and 4 depict the distribution of 12 SNP types in different age groups among female and male patients. Overall, the proportion of $C>T$ mutations in the SARS-CoV-2 genomes from females is higher than the $\mathrm{C}>\mathrm{T}$ proportion in the SARS-CoV-2 genomes from males, except for ages between 6 and 19 and ages older than 90 . Therefore, we can deduce that the RNA editing has an age and gender preference, and is therefore more likely to happen or become stronger for females who are older than 90 years old or under 5 years old.
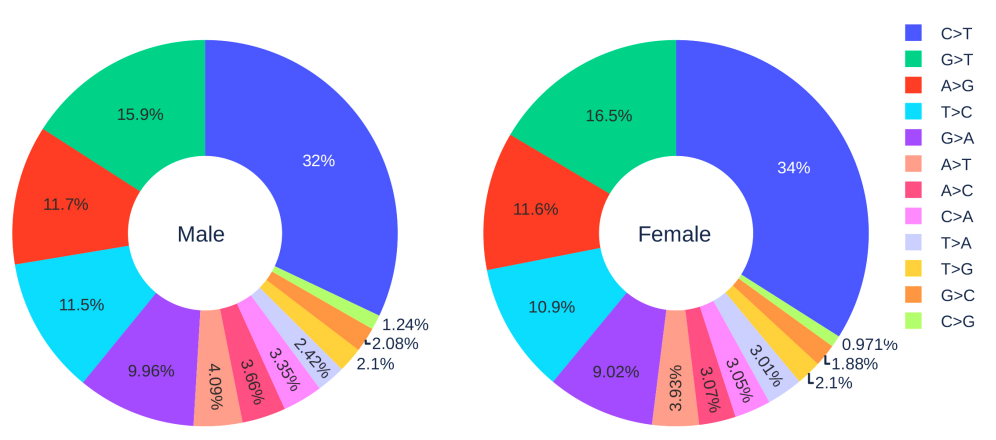

Figure 2. The distribution of 12 SNP types among unique mutations in the SARS-CoV-2 genome isolates from two gender groups. The total number of records in the female group is 5762 and the total number of records in the male group is 7012 .

\subsubsection{Geographic Analysis}

In this section, we analyze the distribution of SARS-CoV-2 mutations in different countries and regions. Limited by the number of complete genome sequences submitted to GISAID that have appropriate labels, we only analyzed the countries with more than 1000 labeled sequences to maintain statistical significance. Table 2 lists the total number of SARS-CoV-2 sequences in the United Kingdom, United States, Australia, and India. The number of sequences with age and gender information is given in Table 2.

Table 2. The number of complete SARS-CoV-2 genomes with age/gender information in the United Kingdom, United States, Australia, India, and the world.

\begin{tabular}{lccc}
\hline Country & Total Counts & Age Counts & Gender Counts \\
\hline United Kingdom & 10,740 & 2159 & 2134 \\
United States & 8729 & 1888 & 2095 \\
Australia & 1329 & 776 & 750 \\
India & 1088 & 1068 & 1071 \\
World & 33,693 & 12,513 & 12,181 \\
\hline
\end{tabular}



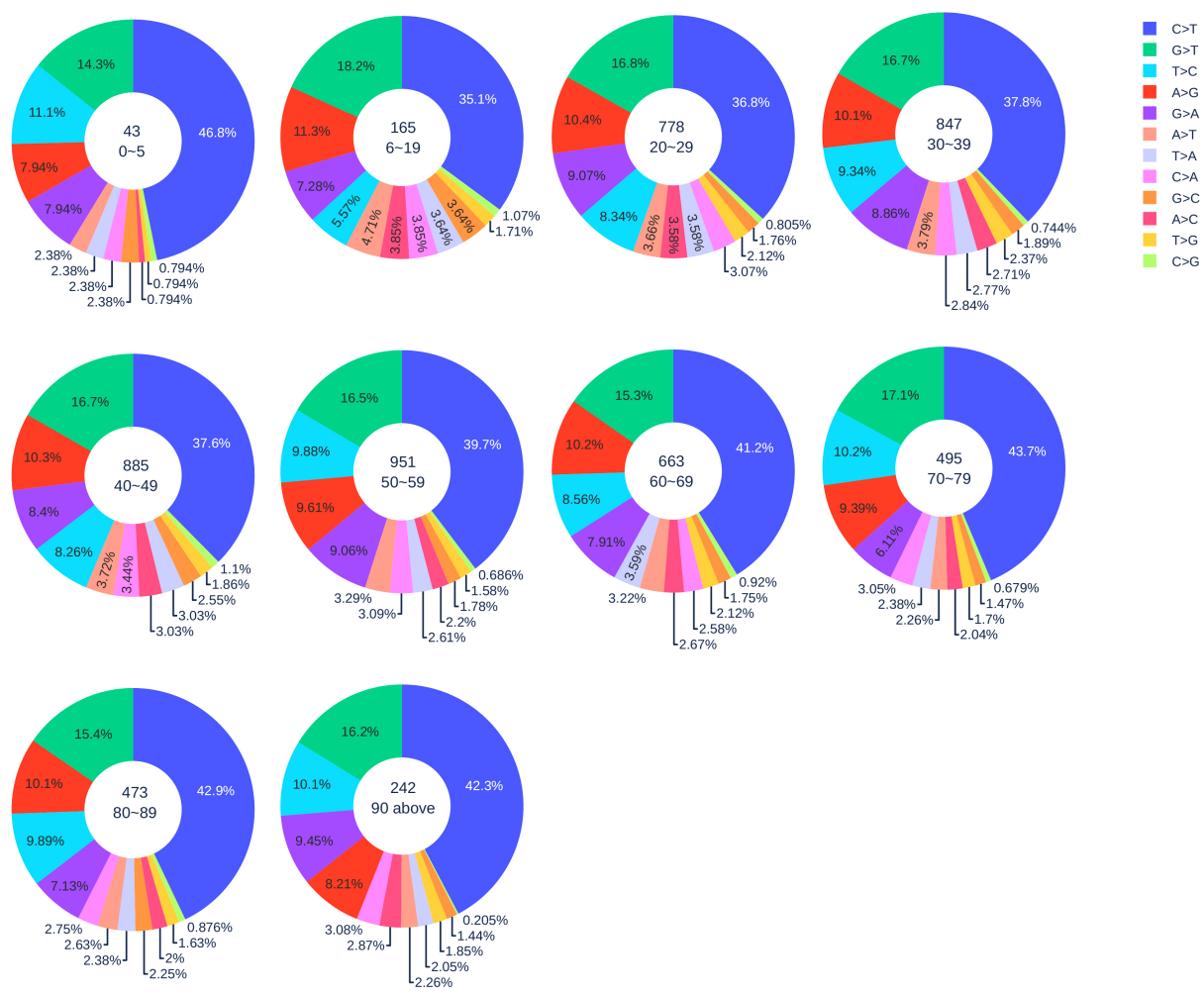

Figure 3. The distribution of $12 \mathrm{SNP}$ types among unique mutations in the SARS-CoV-2 genome isolates from different age groups among female patients. The text inside each circle represents the total number of records that have age information for different age groups.
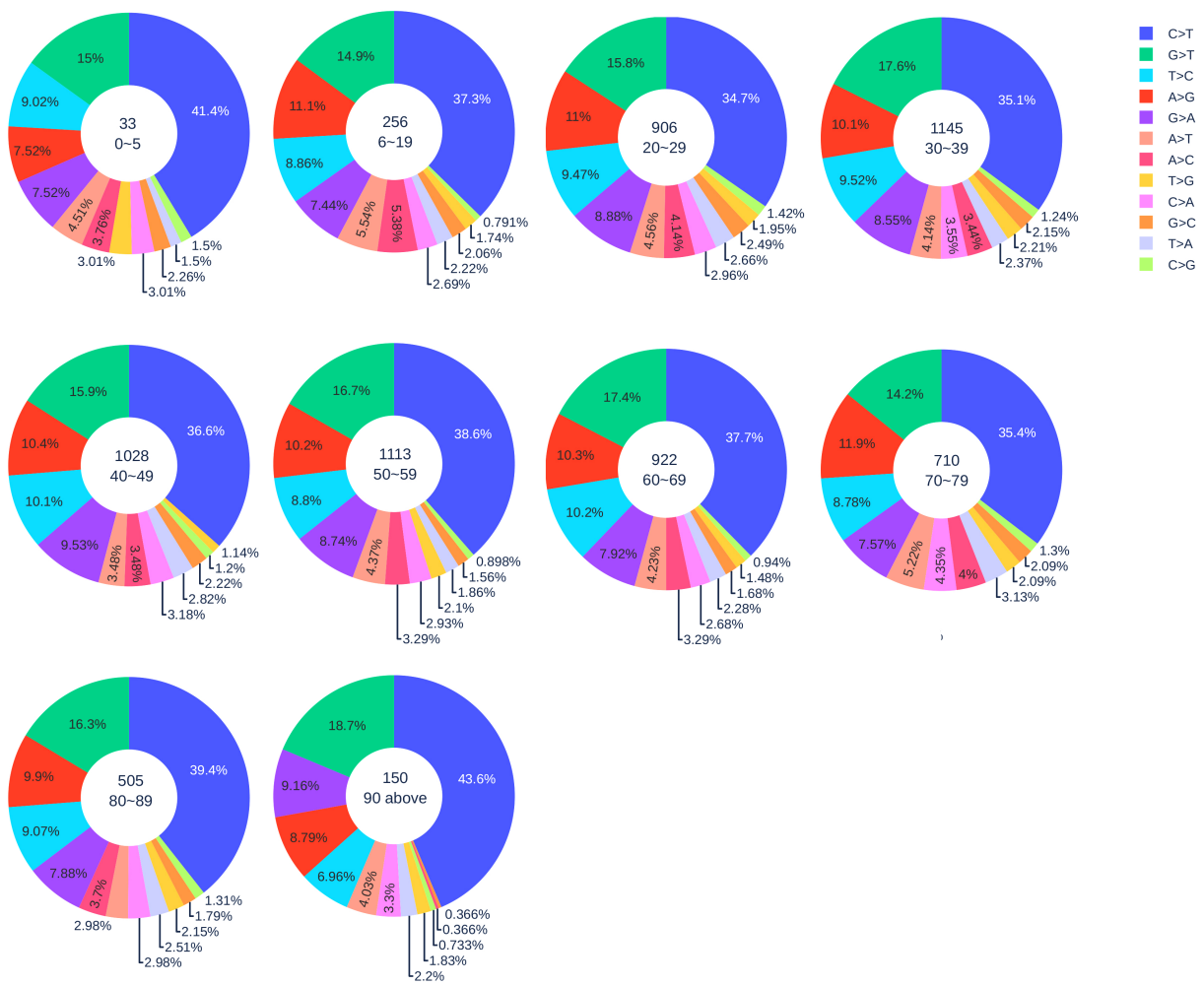

Figure 4. The distribution of 12 SNP types among unique mutations in the SARS-CoV-2 genome isolates from different age groups among male patients. The text inside each circle represents the total number of records that have age information for different age groups. 
Table 3 illustrates the $\mathrm{C}>\mathrm{T}$ ratios in the SARS-CoV-2 genome isolates from different age groups in the United Kingdom, United States, Australia, and India, respectively. We can see that the SARS-CoV-2 genome isolates from the United Kingdom patients have the highest ratio of $C>T$ compared to those from the other three countries. It is interesting to note that the SARS-CoV-2 genome isolates from the patients older than 80 years old from the United Kingdom and Australia have less $C>T$ mutations, which is not consistent with the global pattern. The distribution of 12 SNP types in the SARS-CoV-2 genome isolates from different age groups in the United Kingdom, United States, Australia, and India can be found in the Supporting Information.

Table 3. The $\mathrm{C}>\mathrm{T}$ ratios in different age groups in the United Kingdom, United States, Australia, India, and the world.

\begin{tabular}{lcccccccc}
\hline Country & $\mathbf{0 - 1 9}$ & $\mathbf{2 0 - 2 9}$ & $\mathbf{3 0 - 3 9}$ & $\mathbf{4 0 - 4 9}$ & $\mathbf{5 0 - 5 9}$ & $\mathbf{6 0 - 6 9}$ & $\mathbf{7 0 - 7 9}$ & $\mathbf{8 0}$ above \\
\hline United Kingdom & $44.4 \%$ & $48.4 \%$ & $48.7 \%$ & $49.8 \%$ & $46.9 \%$ & $46.6 \%$ & $48.0 \%$ & $41.7 \%$ \\
United States & $51.0 \%$ & $45.4 \%$ & $44.1 \%$ & $40.0 \%$ & $41.6 \%$ & $40.7 \%$ & $47.6 \%$ & $45.6 \%$ \\
Australia & $35.8 \%$ & $43.1 \%$ & $44.1 \%$ & $41.6 \%$ & $45.5 \%$ & $41.7 \%$ & $45.6 \%$ & $42.0 \%$ \\
India & $39.0 \%$ & $38.2 \%$ & $38.2 \%$ & $35.2 \%$ & $42.4 \%$ & $40.9 \%$ & $46.7 \%$ & $55.0 \%$ \\
\hline
\end{tabular}

Figure 5 illustrates the distribution of 12 SNP types in six continents. The SARS-CoV-2 genome isolates from Europe, Asia, and North America patients have a relatively low $\mathrm{C}>\mathrm{T}$ mutation ratio (less than $35 \%$ ), while the reversed $\mathrm{T}>\mathrm{C}$ mutation ratio is relatively high (greater than $10 \%$ ). When employing the Z-test between the data in the world and in Europe, Asia, and North America, the $p$-values are all less than $10^{-5}$, which means that the $\mathrm{C}>\mathrm{T}$ and $\mathrm{T}>\mathrm{C}$ ratios in Europe, Asia, and North America are not at the same level as the global ratio. On the contrary, South America, Oceania, and Africa have higher $\mathrm{C}>\mathrm{T}$ ratios but a lower $\mathrm{T}>\mathrm{C}$ ratio. It worth noting that the $\mathrm{C}>\mathrm{T}$ mutation ratios in the SARS-CoV-2 genome isolates from Oceania and Africa are more than $10 \%$ higher than those of Asia, Europe, and North America. This result indicates that the APOBEC editing may be more active, and the counterattack of SARS-CoV-2 might be weakened by the strong immune response in the populations of Oceania and Africa.

African Americans, as an ethnic group of Americans with total or partial ancestry from Africa, are genetically associated with Africans. There have been many concerns about the fact that they are disproportionately affected by COVID-19 (https:/ / www.cdc.gov/coronavirus / 2019-ncov / community/health-equity/race-ethnicity.html). The present finding indicates that the immune systems of African Americans may also overreact to SARS-CoV-2 infection by excessive gene editing.

Another interesting issue is that $\mathrm{A}>\mathrm{G}$ mutation ratios of genome isolates from Oceania and Africa are very low $(<9 \%)$. In contrast, the $A>G$ mutation ratios of genome isolates from other regions are significantly higher $(>11 \%)$. The Z-test was also employed to prove that our deduction is statistically significant. For example, when we extracted the number of $A>G$ mutations in Oceania and Asia for calculation, the $p$-value was 0.015 , which is less than the significance level 0.05. Similarly, we repeated the procedure. For patients in Oceania and North America, Oceania and South America, Oceania and Europe, all the $p$-values are less than the significance level 0.05 . These results indicate that Asia and Europe populations may have adopted significantly different genetic and molecular mechanisms in their immune response to viral infection compared to those of Oceania and Africa. Further studies are required to fully understand these differences. 

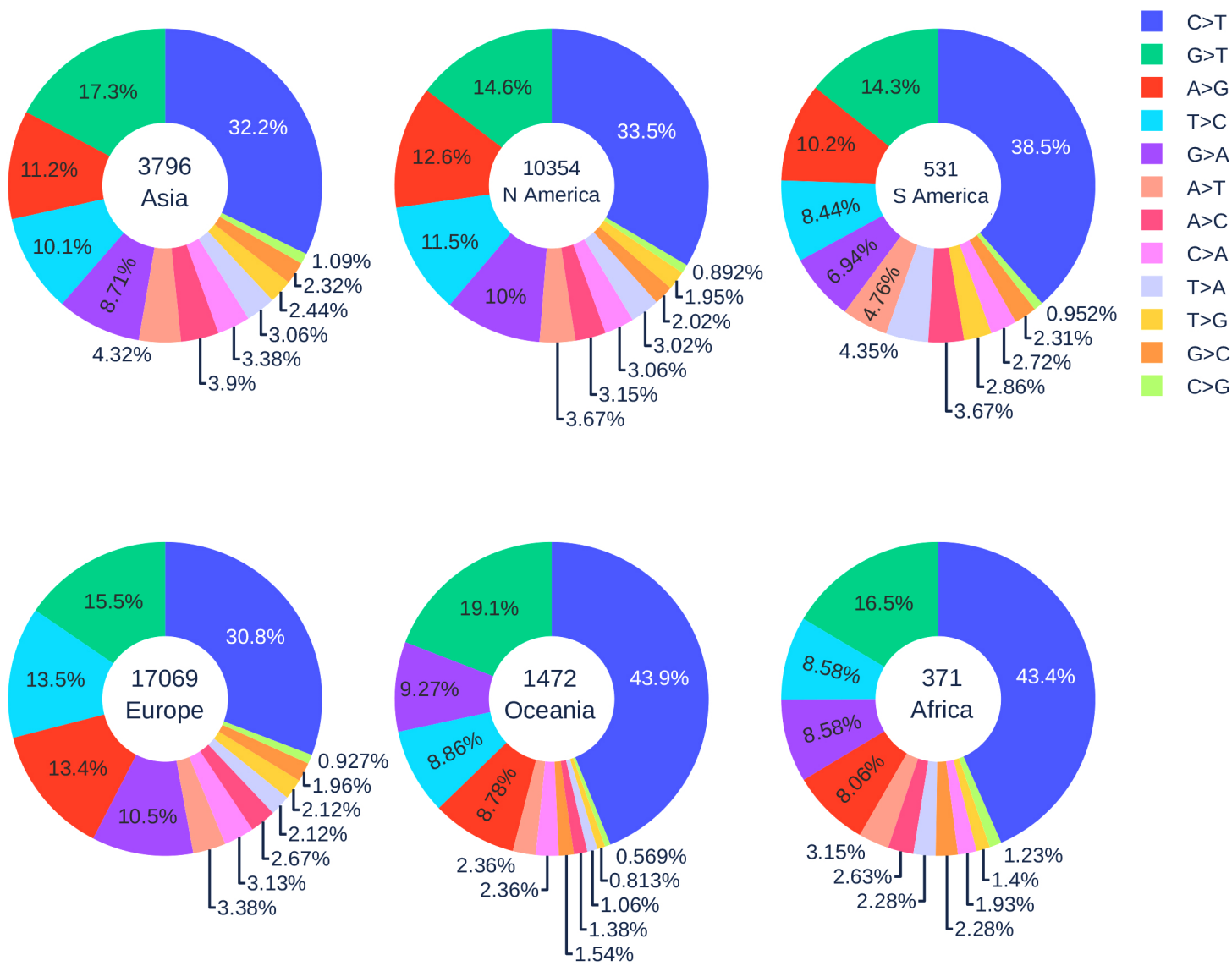

Figure 5. The distribution of 12 SNP types among unique mutations in the SARS-CoV-2 genome isolates in six continents. The text inside each circle represents the total number of records in each continent.

\subsection{The SNP Preferences on Sequence Contexts}

The mutation preferences in sequence contexts may be used to predict the mutational signatures from genome sequences. Despite numerous studies of the mutation contexts in APOBEC editing inhuman cells, little is known of the mutation contexts in the SARS-CoV-2 genome. As we have a large number of SNP mutations from SARS-CoV-2 genomes, here, we discuss the mutation frequencies from 2-mer and 3-mer sequence contexts. We present 4-mer sequence contexts in the Supporting Information.

In general, the patterns discussed in this section are consistent with those presented in Section 3.1.1. However, this section offers more detailed information about mutational signatures.

For mutation motifs of SNPs at the first position of 2-mers Figure 6a, we observe that motif 2-mer $\mathrm{CW}$ (where $\mathrm{W}$ is either $\mathrm{A}$ or $\mathrm{T}$ ) for the $\mathrm{C}>\mathrm{T}$ mutation is the predominant context. Similarly, for mutation motifs of the SNPs at the second position of 2-mers Figure 6b, motif 2-mer WC for C > T mutation is the predominant context. These results are consistent with the previous study that TCW contexts (where $\mathrm{W}=\mathrm{A}$ or $\mathrm{T}$ ) are predominantly caused by the APOBEC-catalyzed deamination of cytosine $(\mathrm{C})$ to thymine $(\mathrm{T})$ or uracil $(\mathrm{U})$ in human cancer cells [42]. 


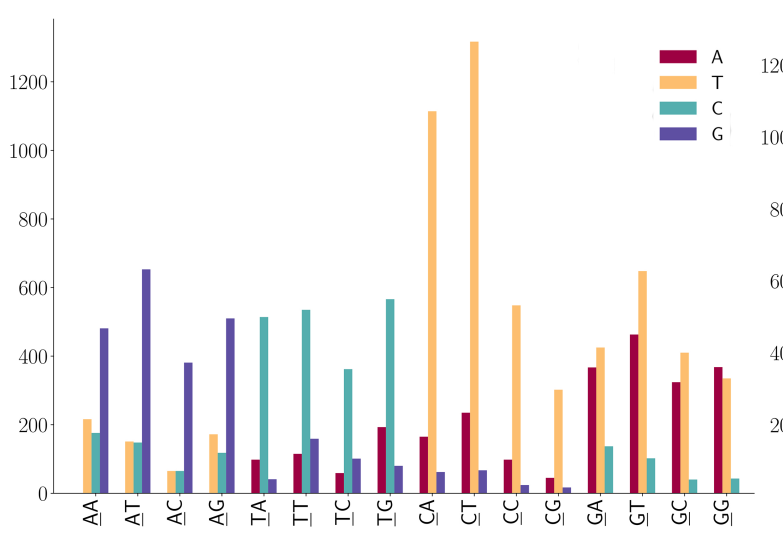

(a)

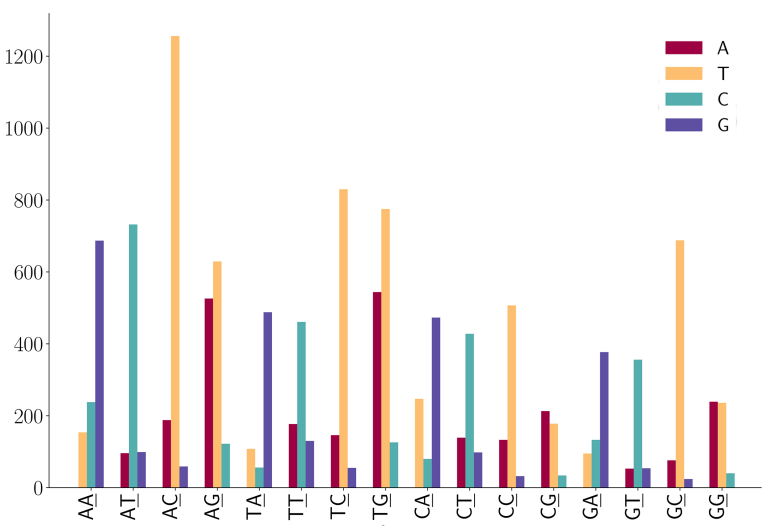

(b)

Figure 6. SNP frequencies on 2-mer motifs. (a) SNP frequencies are at the first position of 2-mer motifs. (b) SNP frequencies are at the second position of 2-mer motifs.

For the SNPs at the first position of 3-mers ( $\underline{A N N}$ or TNN) (Figure 7a), we observe the following mutation patterns.

(1) ANN has high A > G mutations;

(2) TNN has a high frequency in $\mathrm{T}>\mathrm{C}$ mutations.

For the SNPs at the first position of 3-mers (CNN or GNN) shown in Figure 7b, we observe the following mutation patterns.

(1) $\underline{C} N$ has a high frequency in $\mathrm{C}>\mathrm{T}$ mutations;

(2) GGA and GGT has a high frequency in $\mathrm{G}>$ A mutations;

(3) GAA has a relatively high frequency in $\mathrm{G}>\mathrm{A}$ mutations;

(4) GGW (where $\mathrm{W}$ is A or T) has relatively high frequency in $\mathrm{G}>\mathrm{T}$ mutations.

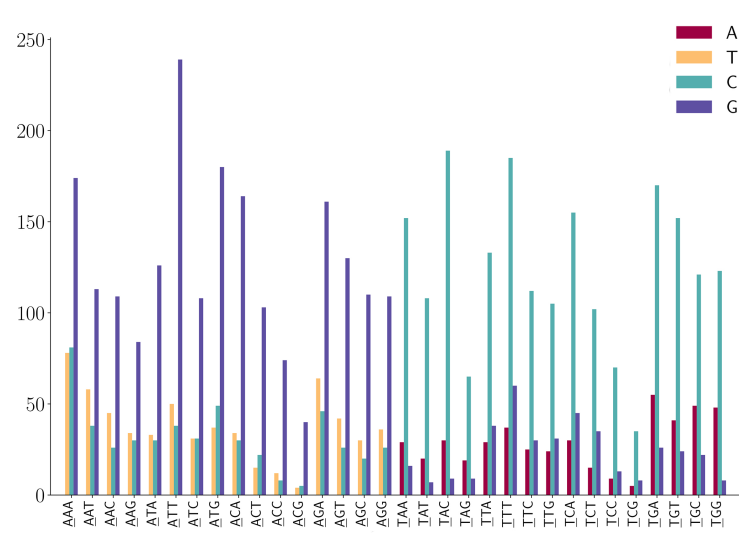

(a)

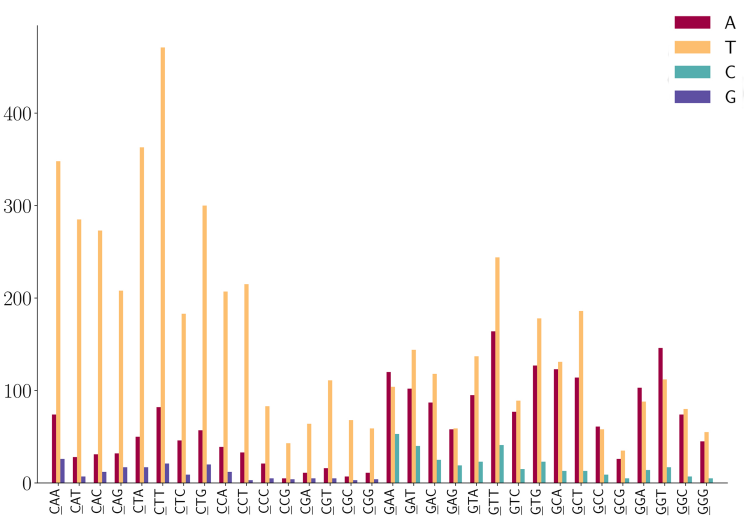

(b)

Figure 7. SNP frequency at the first positions of the 3-mer motifs. (a) A or T is at the first position of 3-mer motifs. (b) $\mathrm{C}$ or $\mathrm{G}$ is at the first position of 3-mer motifs.

For the SNPs at the second position of the 3-mers (NAN or NTN), as shown in Figure 8a, we observe the following mutation patterns.

(1) N $\underline{A}$ has a high frequency in $\mathrm{A}>\mathrm{G}$ mutations;

(2) NTN has a high frequency in $\mathrm{T}>\mathrm{C}$ mutations;

(3) The $\mathrm{A}>\mathrm{C}$ mutation also has a larger proportion in $\mathrm{AAW}$ (where $\mathrm{W}$ is $\mathrm{A}$ or $\mathrm{T}$ ). 


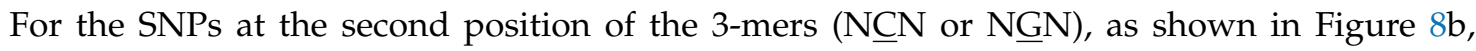
we observe the following mutation patterns.

(1) WG $\mathrm{N}$ (where $\mathrm{W}$ is $\mathrm{A}$ or $\mathrm{T}$ ) has a $\mathrm{G}>\mathrm{T}$ dominated mutation except for $\mathrm{A} \underline{G}$;

(2) SGN (where $S$ is $G$ or $C$ ) has $G>A$ dominated mutations;

(3) AGG has high $\mathrm{G}>\mathrm{A}$ mutations;

(4) Characteristic combinations S $\underline{C} G$ (where $S$ is $G$ or $C$ ) are stable and only a few $C>$ G mutations are detected;

(5) Characteristic combinations GGS (where $\mathrm{S}$ is $\mathrm{G}$ or $\mathrm{C}$ ) are stable, only a few $\mathrm{G}>\mathrm{C}$ mutations are detected.

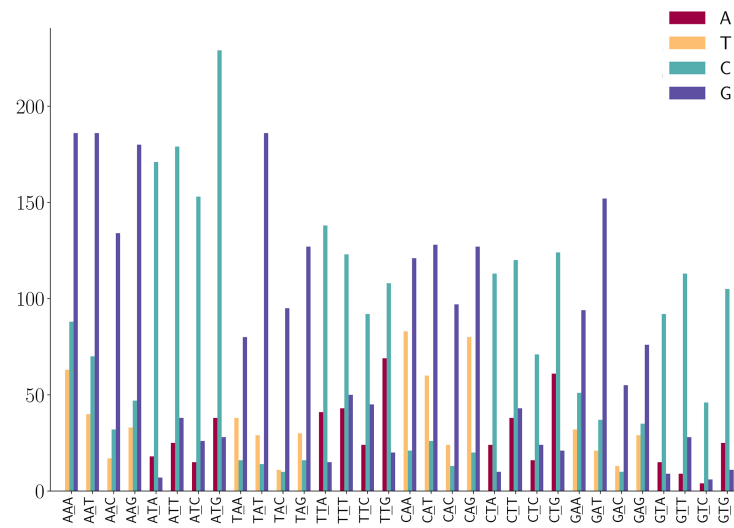

(a)

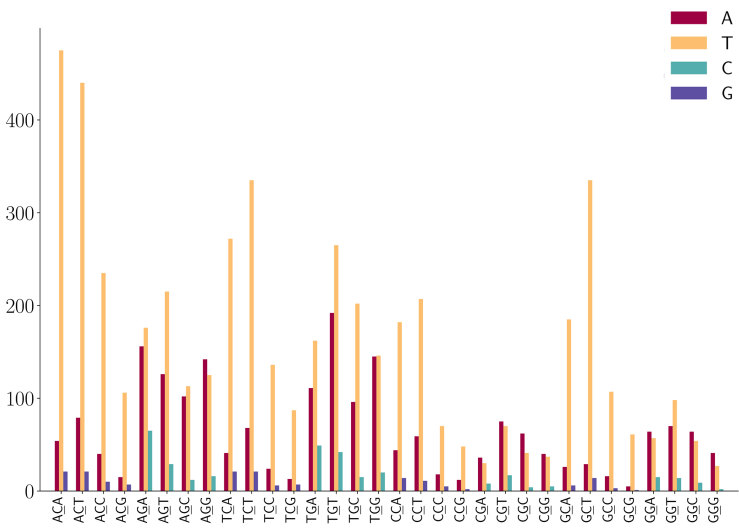

(b)

Figure 8. SNP frequency at the second position of 3-mer motifs. (a) A or T is at the second position of 3-mer motifs. (b) $\mathrm{C}$ or $\mathrm{G}$ is at the second position of 3-mer motifs.

For the SNPs at the third position of 3-mers (NNA or NNT) a shown in Figure 9a, we observe the following mutation patterns.

(1) A > G mutation has a high frequency in NN

(2) $\mathrm{T}>\mathrm{C}$ mutation has a high frequency in NNT;

(3) $\mathrm{T}>\mathrm{C}$ mutation is dominated in NGT and only a few T $>$ A and T $>\mathrm{G}$ are found in the sequence context of NGT.

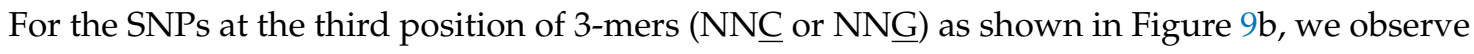
the following mutation patterns.

(1) NNC has a high frequency in $\mathrm{C}>\mathrm{T}$ mutations;

(2) $\mathrm{G}>\mathrm{T}$ mutation has a high frequency in NNG;

(3) G $>$ A is also highly expressed in the sequence context of NNG;

(4) Characteristic combinations CGC are stable and the mutations on these patterns are most likely to be $\mathrm{C}>\mathrm{T}$ transitions. 


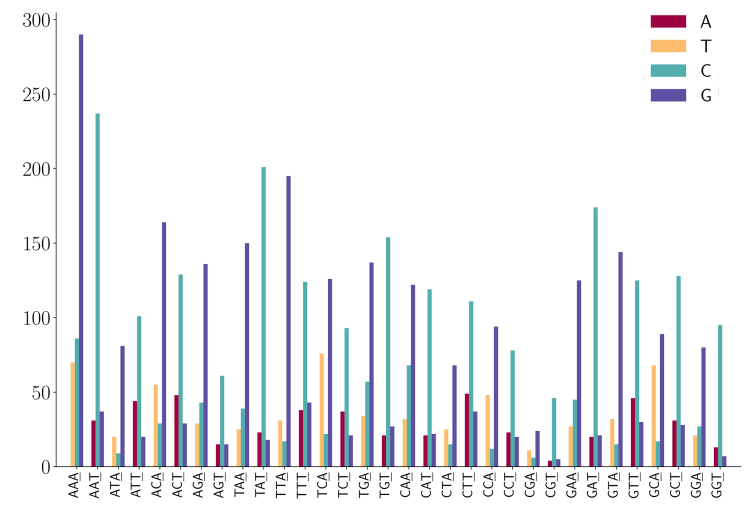

(a)

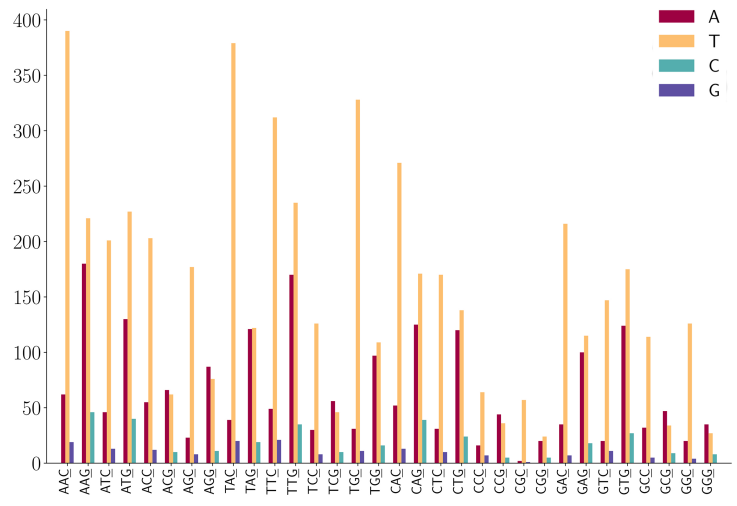

(b)

Figure 9. SNP frequency at the third position of the 3-mer motifs. (a) A or T is at the third position of 3-mer motifs. (b) C or G is at the third position of 3-mer motifs.

\subsection{Coronavirus Evolution}

It is reasonable to assume that the five coronaviruses, SARS-CoV (2003) [43], Bat-SL-BM48-31 (2008) [44], Bat-SL-CoVZC45 (2017) [45], Bat-SL-RaTG13 (2013) [46] and SARS-CoV-2 (2019) [2], are of the same origin but differ from each other by their evolutionary stages. The data collection date of Bat-SL-RaTG13 (2013) was denoted as 24 July 2013, while the data were not uploaded to the GISIAD database until 27 January 2020. Figure 10 shows the mutation ratio among these five genomes. First, similar to the SARS-CoV-2 mutations listed in Table 1, four transition types (i.e., A $>$ C, C > A, C > T, and $\mathrm{T}>\mathrm{C}$ ) still have high mutation ratios. Notably, the $\mathrm{C}>\mathrm{T}$ type has the highest ratio, indicating that host immune response still plays the major role. However, transversion type $G>T$ is not as important as in the SARS-CoV-2 mutations discussed earlier. Nonetheless, transversion types A $>\mathrm{T}$ and $\mathrm{T}>\mathrm{A}$ appear on the top six mutation types.
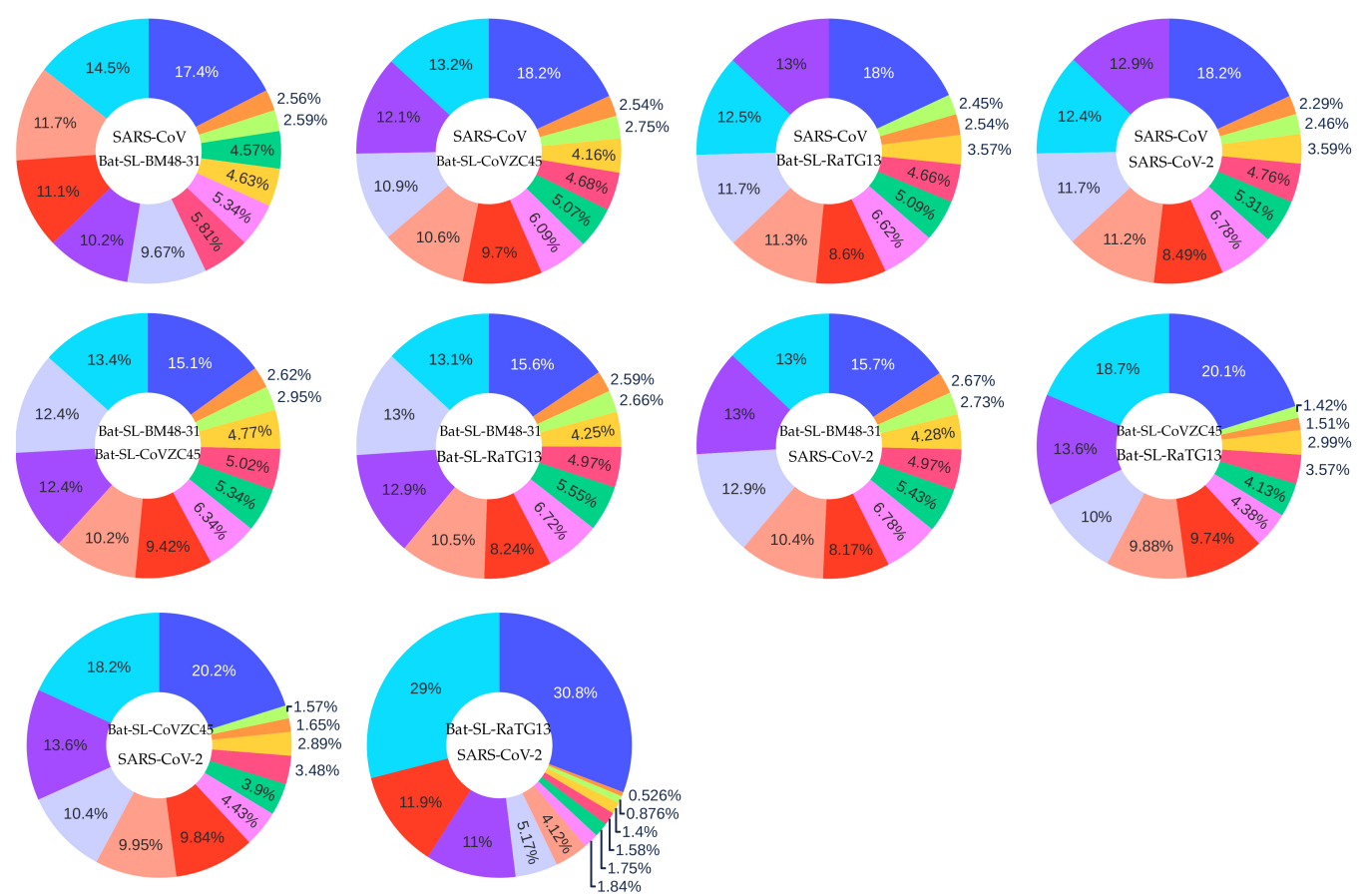

Figure 10. The distribution of 12 SNP types among SARS-CoV, Bat-SL-BM48-31, Bat-SL-CoVZC45, Bat-SL-RaTG13, and SARS-CoV-2. Here, the text at the top represents the reference genome and the text at the bottom represents the mutant sequence. 
We hypothesize that gene editing via $\operatorname{APOBEC}(C>T)$ and $\operatorname{ADAR}(A>G)$ is a driving force for RNA viral evolution, as shown in Table 1 . Viruses may fight the host immune response with either defective repair or reversed mutations $(\mathrm{T}>\mathrm{C}$ ) within survived isolates. Therefore, the $\mathrm{T}>\mathrm{C}$ mutation rate would decrease during evolution. We are interested in not only the $\mathrm{C}>\mathrm{T}$ transition ratio, but also the ratio of $C>T$ over $T>C$, the reversed transitions. From Figure 10, we can calculate the $C>T$ over $\mathrm{T}>\mathrm{C}$ ratios among different SARS-like species which are listed in Table 4.

Table 4. The C > T over T > C ratios among SARS-CoV (2003), Bat-SL-BM48-31 (2008), Bat-SL-CoVZC45 (2017), Bat-SL-RaTG13 (2013), and SARS-CoV-2 (2019).

\begin{tabular}{llccc}
\hline From & To & C > T Ratio & T > C Ratio & C > T/T > C Ratio \\
\hline SARS-CoV-2 reference genome & 33693 SARS-CoV-2 genomes & $24.06 \%$ & $14.53 \%$ & 1.66 \\
SARS-CoV & Bat-SL-BM48-31 & $17.40 \%$ & $14.50 \%$ & 1.20 \\
SARS-CoV & Bat-SL-CoVZC45 & $18.20 \%$ & $13.20 \%$ & 1.37 \\
SARS-CoV & Bat-SL-RaTG13 & $18.00 \%$ & $12.50 \%$ & 1.50 \\
SARS-CoV & SARS-CoV-2 & $18.20 \%$ & $12.40 \%$ & 1.47 \\
Bat-SL-BM48-31 & Bat-SL-CoVZC45 & $15.10 \%$ & $13.40 \%$ & 1.13 \\
Bat-SL-BM48-31 & Bat-SL-RaTG13 & $15.60 \%$ & $13.10 \%$ & 1.19 \\
Bat-SL-BM48-31 & SARS-CoV-2 & $15.70 \%$ & $13.00 \%$ & 1.21 \\
Bat-SL-CoVZC45 & Bat-SL-RaTG13 & $20.10 \%$ & $18.70 \%$ & 1.07 \\
Bat-SL-CoVZC45 & SARS-CoV-2 & $20.20 \%$ & $18.20 \%$ & 1.11 \\
Bat-SL-RaTG13 & SARS-CoV-2 & $30.80 \%$ & $29.00 \%$ & 1.06 \\
\hline
\end{tabular}

It is seen that viral evolution order may be determined by the $\mathrm{T}>\mathrm{C}$ over $\mathrm{T}>\mathrm{C}$ ratio. Through this analysis, we have the following evolution order for the aforementioned coronaviruses: SARS-CoV (2003) $\rightarrow$ Bat-SL-BM48-31 (2008) $\rightarrow$ Bat-SL-CoVZC45 (2017) $\rightarrow$ Bat-SL-RaTG13 (2013) $\rightarrow$ SARS-CoV-2 (2019) $\rightarrow 33693$ SARS-CoV-2 genome isolates (2020). Here, we have one reversed order between Bat-SL-CoVZC45 (2017) $\rightarrow$ Bat-SL-RaTG13 (2013). This may happen for a few reasons. First, these coronaviruses may not be of the same origin. Second, the data collection date may not be accurate. The sequence of Bat-SL-RaTG13 (2013) was not uploaded until 2020. Finally, our method may admit a few counterexamples.

\section{Discussion}

\subsection{Comparison of Unique Mutations and Non-Unique SARS-CoV-2 Mutations}

The distribution of unique SNP types of 33,693 SARS-CoV-2 isolates is listed in Table 1. The C > T SNP type is remarkably higher than other mutation types. From the distribution of the 12 SNP types, we may infer that the excessive $\mathrm{C}>\mathrm{T}$ transitions cannot explained by random mutations; instead, hypermutation $\mathrm{C}>\mathrm{T}$ is due to the cytosine-to-uridine deamination gene editing in human host response. It is interesting to know the distribution of non-unique SNP types.

Figure 11 presents a comparison of the ratios of 12 SNP types among unique and non-unique mutations over all the SARS-CoV-2 genome isolates. The most striking feature is that the $\mathrm{C}>\mathrm{T}$ ratio is more than doubled in the non-unique mutations, which indicates the overwhelming host immune response to viral infection. Another interesting feature is that the inverse transition $\mathrm{T}>\mathrm{C}$ has a dramatic reduction of $68 \%$ from the unique mutation ratio to the non-unique mutation ratio. These changes reflect the fact that many $\mathrm{C}>\mathrm{T}$ mutations are high-frequency ones, whereas virus-reversing $\mathrm{T}>\mathrm{C}$ mutations are low-frequency in nature. The same explanation applies to many mutation types in Figure 11 that have significantly reduced their ratios in the non-unique mutations. However, we observed that the ratios of mutation types $A>G, G>T$, and $G>A$ do not change much in the non-unique mutations, reflecting the fact that these mutation types maintain a near-average frequency. 


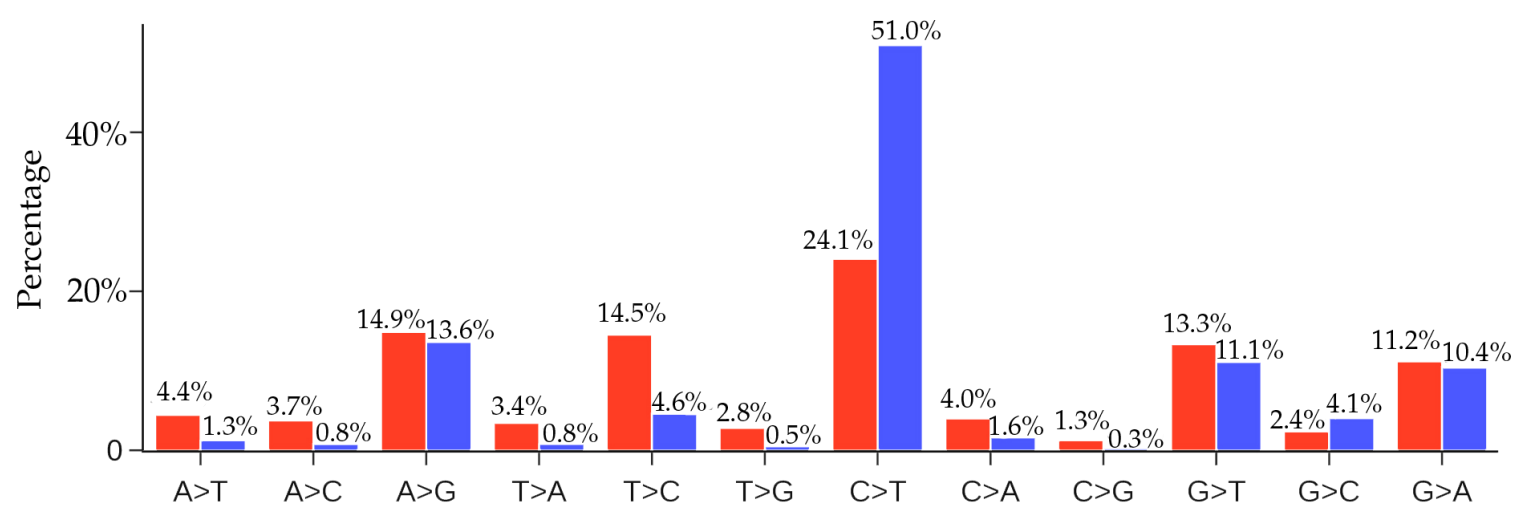

Figure 11. Comparison of the ratios of 12 SNP types among unique mutations (red) and non-unique mutations (blue) in SARS-CoV-2 genomes globally. Here, if we count the same mutation that appears in different SARS-CoV-2 isolates only once, we call those mutations unique mutations. If we count the same mutation in different SARS-CoV-2 isolates repeatedly according to their frequency, then all of the mutations that are detected in the complete SARS-CoV-2 genome sequences are called non-unique mutations.

Figure 11 shows that the second most frequent mutation type is $\mathrm{A}>\mathrm{G}$ transitions, standing at 13.6\%. The combined $\mathrm{C}>\mathrm{T}$ and $\mathrm{A}>\mathrm{G}$ transition types account for nearly $65 \%$ of all mutations. Therefore, host gene editing via APOBEC and ADAR is the major driving force of SARS-CoV-2 evolution.

Neutralizing antibodies play a significant role in the clearance of viruses and have been considered a crucial immune artifact for the defense or treatment of viral diseases. However, a clinical study shows that five percent of people recovered from COVID-19 had no detectable antibodies [47]. Another observation is that there are a large number of asymptomatic carrier transmissions of COVID-19 [48]. The reason for the no-antibody COVID-19 recovery and asymptomatic carriers is unknown. From the mutation analysis in this study, APOBEC3 RNA editing is implicated as a strong secondary defense system for the mutating virus and, consequently, for mitigating infection. We postulate that COVID-19 recoveries or convalescents without antibody, and some asymptomatic carriers, are probably due to the increased APOBEC3 activity in host immune systems.

\subsection{Comparison of Unique Mutations and Non-Unique MERS-CoV-2 Mutations}

In this section, we would like to know whether there are similar gene editing behaviors associated with other virus transmission and infection rates. We note that the distribution of SNP types depends on the viral structure, function and its interaction with the host, the degree of infection spread, and the duration of the viral outbreak. Therefore, it is not very meaningful to directly compare the distributions of the SNP types of two viral outbreaks. Nonetheless, we considered the recent Middle East respiratory syndrome-related coronavirus (MERS-CoV) outbreak. We downloaded 523 MERS-CoV sequences from the GenBank. By using the MERS-CoV isolate HCoV-EMC/2012 as the reference (Genbank access number: NC_019843.3), we present the comparison of the ratios of 12 SNP types among unique and non-unique mutaitons over all the MERS-CoV genome isolates in Figure 12. From Figures 11 and 12 , it can be seen that the $\mathrm{C}>\mathrm{T}$ ratio in SARS-CoV-2 isolates is higher than the $\mathrm{C}>\mathrm{T}$ ratio in MERS-CoV isolates. It is noteworthy that although the $C>T$ ratio is not the highest in the unique case, the $C>T$ is the top-ranked mutation in the non-unique case, indicating that gene-editing may also be active in MERS-CoV infected hosts. 


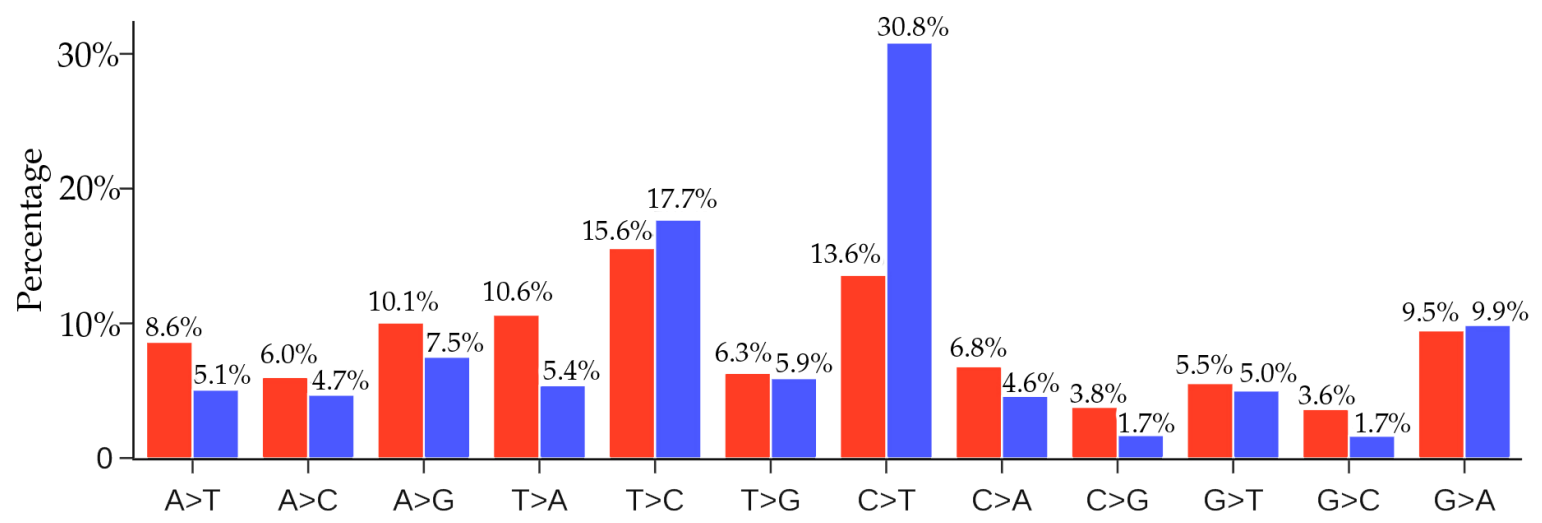

Figure 12. Comparison of the ratios of $12 \mathrm{SNP}$ types among unique mutations (red) and non-unique mutations (blue) in MERS-CoV genome isolates. Here, if we count the same mutation that appears in different MERS-CoV isolates only once, we call those mutations unique mutations. If we count the same mutation in different MERS-CoV isolates repeatedly according to their frequency, then all of the mutations that are detected in the complete MERS-CoV genome sequences are called the non-unique mutations.

\subsection{Gene- and Protein-Specific Analysis}

Figure 13 illustrates the distribution of mutations on the complete SARS-CoV-2 genome. The $y$-axis represents the natural $\log$ frequency for each mutation on a specific position of the complete SARS-CoV-2 genome. We also create a website to report single mutations and update it regularly. We recommend that interested readers go to our website (https:/ / users.math.msu.edu/users/weig/ SARS-CoV-2_Mutation_Tracker.html) for detailed information.

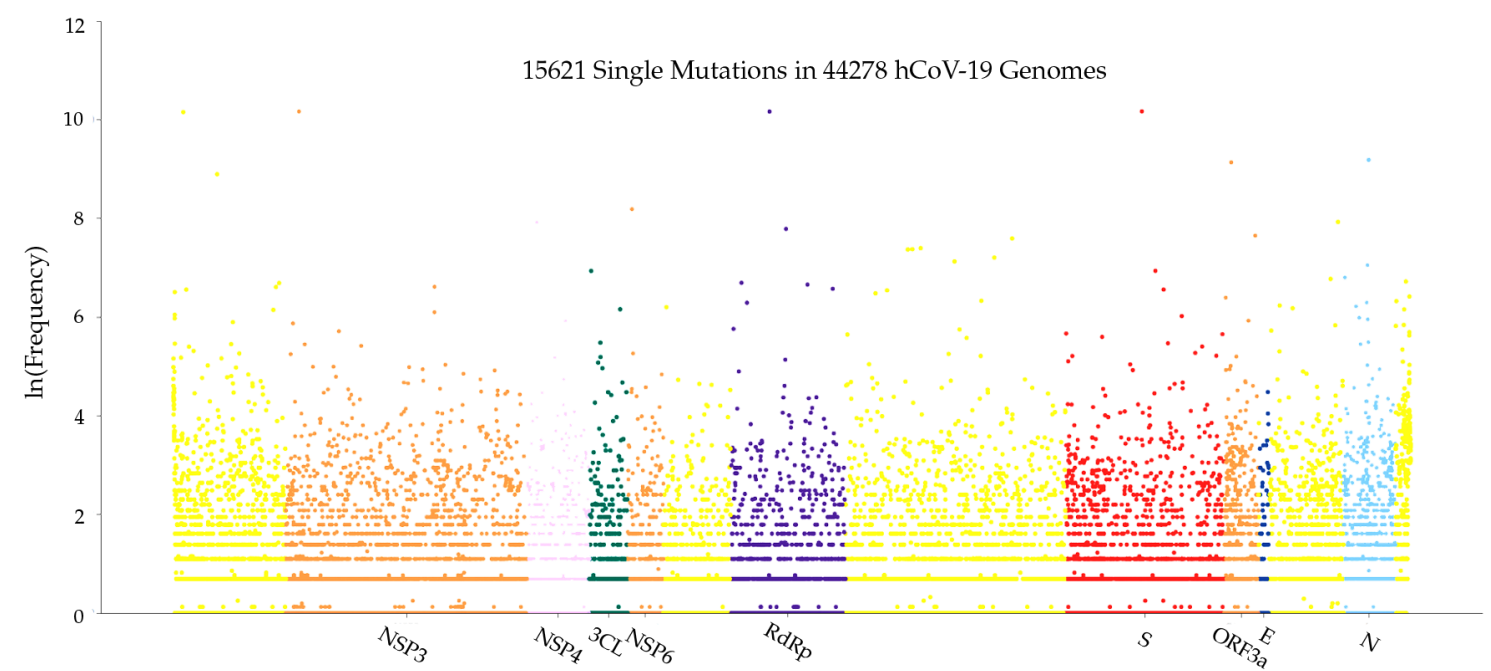

Figure 13. Genome-wide SARS-CoV-2 mutation distribution. The $y$-axis represents the natural $\log$ frequency for each mutation on a specific position of the complete SARS-CoV-2 genome. While only a few landmark positions are labeled with gene (protein) names, the relative positions of other genes (proteins) can be inferred from Table 5.

Furthermore, we calculated the $\mathrm{C}>\mathrm{T}$ ratios on all SARS-CoV-2 proteins. Table 5 shows the $\mathrm{C}>\mathrm{T}$ ratios in 26 SARS-CoV-2 proteins. We can see that NSP9 has the highest $C>$ T ratio, and ORF7b protein has the lowest $C>T$ ratio. 
Table 5. $\mathrm{C}>\mathrm{T}$ ratios on $26 \mathrm{SARS}-\mathrm{CoV}-2$ proteins. For each gene, the "corrected $\mathrm{C}>\mathrm{T}$ ratio" is computed by dividing its $\mathrm{C}>\mathrm{T}$ ratio with the ratio of $\mathrm{C}$ in the gene.

\begin{tabular}{lcccc}
\hline Gene Type & Gene Site & Gene Length & C > T Ratio & Corrected C > T Ratio \\
\hline NSP1 & $266: 805$ & 540 & $29.0 \%$ & 1.35 \\
NSP2 & $806: 2719$ & 1914 & $26.1 \%$ & 1.41 \\
NSP3 & $2720: 8554$ & 5835 & $25.4 \%$ & 1.52 \\
NSP4 & $8555: 10054$ & 1500 & $30.7 \%$ & 1.73 \\
NSP5(3CL) & $10055: 10972$ & 918 & $32.7 \%$ & 1.84 \\
NSP6 & $10973: 11842$ & 870 & $23.7 \%$ & 1.43 \\
NSP7 & $11843: 12091$ & 249 & $29.0 \%$ & 1.47 \\
NSP8 & $12092: 12685$ & 594 & $28.4 \%$ & 1.58 \\
NSP9 & $12686: 13024$ & 339 & $34.4 \%$ & 1.82 \\
NSP10 & $13025: 13441$ & 417 & $30.4 \%$ & 1.51 \\
NSP11 & $13442: 13480$ & 39 & $33.3 \%$ & 1.86 \\
RNA-dependent-polymerase & $13442: 16236$ & 2796 & $25.4 \%$ & 1.42 \\
Helicase & $16237: 18039$ & 1803 & $26.5 \%$ & 1.42 \\
3'-to-5' exonuclease & $18040: 19620$ & 1581 & $27.1 \%$ & 1.48 \\
endoRNAse & $19621: 20658$ & 1038 & $19.8 \%$ & 1.37 \\
2'-O-ribose methyltransferase & $20659: 21552$ & 894 & $24.3 \%$ & 1.52 \\
Spike protein & $21563: 25384$ & 3819 & $21.3 \%$ & 1.13 \\
ORF3a protein & $25393: 26220$ & 825 & $22.8 \%$ & 1.08 \\
Envelope protein & $26245: 26472$ & 225 & $22.4 \%$ & 1.14 \\
Membrane glycoprotein & $26523: 27191$ & 666 & $26.4 \%$ & 1.21 \\
ORF6 protein & $27202: 27387$ & 183 & $16.6 \%$ & 1.19 \\
ORF7a protein & $27394: 27759$ & 363 & $21.9 \%$ & 1.04 \\
ORF7b protein & $27756: 27887$ & 129 & $8.3 \%$ & 0.67 \\
ORF8 protein & $27894: 28259$ & 363 & $18.1 \%$ & 1.03 \\
Nucleocapsid protein & $28274: 29533$ & 1257 & $24.0 \%$ & 0.96 \\
ORF10 protein & $29558: 29674$ & 114 & $28.4 \%$ & 1.58 \\
\hline
\end{tabular}

For each gene, the corrected $\mathrm{C}>\mathrm{T}$ ratio is computed by the original $\mathrm{C}>\mathrm{T}$ ratio divided by the ratio of $C$ in the gene. We further found that the Pearson correlation coefficient between the $C>T$ ratios and corrected $\mathrm{C}>\mathrm{T}$ ratios over all genes in the SARS-CoV-2 genome is 0.86 , which indicates that the $C>T$ ratio may be not affected much by the ratio of $C$ nucleotides. It is the structure and function of each gene that determine its $C>T$ ratio.

\section{Conclusions}

We use genotyping to analyze the mutation types and their distributions of SARS-CoV-2 genome isolates. We show that host gene editing, namely APOBEC (apolipoprotein B mRNA editing enzyme, catalytic polypeptide-like) and ADAR (adenosine deaminases acting on RNA), are the main driven forces of SARS-CoV-2 evolution, accounting for near $65 \%$ of recorded mutations. We reveal that the immune systems of children under age five and the elderly appear to overreact to SARS-CoV-2 infection and may be at high risk from COVID-19. Some minor gender dependence in immune response was also detected. We uncover that the populations of Oceania and Africa react significantly more intensely to SARS-CoV-2 infection than those of Europe and Asia. Our study indicates that while systemic health and social inequities have put African Americans at increased risk of getting sick from COVID-19, their immune systems' overreaction to viral infection may put them at increased risk of dying from COVID-19. The mutational signatures have been analyzed to explore the preferred gene editing environments. Finally, we show that the ratio of mutation type $\mathrm{C}>\mathrm{T}$ over $\mathrm{T}>\mathrm{C}$ may be used to indicate the evolution direction and distinguish the evolution order between two genome sequences of the same origin. 
Supplementary Materials: The following are available online at http://www.mdpi.com/1999-4915/12/10/ $1095 /$ s1. Supporting information is available for supplementary figures, including the distribution of 12 SNP types among non-unique mutations, the distribution of 12 SNP types between each pair of 10 coronaviruses, and 4-mer analysis of mutational signatures. Supplementary tables are available for GISAID IDs and GISAID acknowledgment.

Author Contributions: Conceptualization, G.-W.W., C.Y. and Y.-H.Z.; methodology, C.Y. and R.W.; software, C.Y., R.W. and Y.H.; validation, C.Y. and R.W.; formal analysis, R.W. and Y.H.; investigation, R.W. and Y.H.; resources, G.-W.W.; data curation, R.W. and Y.H.; writing-original draft preparation, R.W.; writing-review and editing, C.Y., Y.-H.Z. and G.-W.W.; visualization, R.W. and Y.H.; supervision, C.Y. and G.-W.W.; project administration, C.Y. and G.-W.W.; funding acquisition, G.-W.W. All authors have read and agreed to the published version of the manuscript.

Funding: This research was funded by NIH grants number GM126189 and AI145504, NSF grants number DMS-1721024, DMS-1761320, and IIS1900473, MICHIGAN ECONOMIC DEVELOPMENT CORPORATION, GEORGE MASON UNIVERSITY award PD45722, BRISTOL-MYERS SQUIBB, and PFIZER.

Acknowledgments: The authors thank The IBM TJ Watson Research Center, The COVID-19 High Performance Computing Consortium, and NVIDIA for computational assistance.

Conflicts of Interest: The authors declare no conflict of interest.

\section{Abbreviations}

The following abbreviations are used in this manuscript:

SARS-CoV-2 Severe Acute Respiratory Syndrome Coronavirus 2

COVID-19 Coronavirus disease 2019

APOBEC Apolipoprotein B mRNA editing enzyme, catalytic polypeptide-like

ADAR Adenosine deaminases acting on RNA

AIDs Activation-induced cytidine deaminases

\section{References}

1. WHO. Coronavirus Disease 2019 (COVID-19) Situation Report-193; WHO: Geneva, Switzerland, 2020.

2. Wu, F.; Zhao, S.; Yu, B.; Chen, Y.-M.; Wang, W.; Song, Z.-G.; Hu, Y.; Tao, Z.-W.; Tian, J.-H.; Pei, Y.-Y.; et al. A new coronavirus associated with human respiratory disease in China. Nature 2020, 579, 265-269. [CrossRef] [PubMed]

3. Xiao, X.; Chakraborti, S.; Dimitrov, A.S.; Gramatikoff, K.; Dimitrov, D.S. The SARS-CoV S glycoprotein: Expression and functional characterization. Biochem. Biophys. Res. Commun. 2003, 312, 1159-1164. [CrossRef] [PubMed]

4. Glowacka, I.; Bertram, S.; Müller, M.A.; Allen, P.; Soilleux, E.; Pfefferle, S.; Steffen, I.; Tsegaye, T.S.; He, Y.; Gnirss, K.; et al. Evidence that TMPRSS2 activates the severe acute respiratory syndrome coronavirus spike protein for membrane fusion and reduces viral control by the humoral immune response. J. Virol. 2011, 85, 4122-4134. [CrossRef] [PubMed]

5. Hoffmann, M.; Kleine-Weber, H.; Schroeder, S.; Krüger, N.; Herrler, T.; Erichsen, S.; Schiergens, T.S.; Herrler, G.; Wu, N.-H.; Nitsche, A.; et al. SARS-CoV-2 cell entry depends on ACE2 and TMPRSS2 and is blocked by a clinically proven protease inhibitor. Cell 2020, 181, 271-280.e8. [CrossRef] [PubMed]

6. McBride, R.; Van Zyl, M.; Fielding, B.C. The coronavirus nucleocapsid is a multifunctional protein. Viruses 2014, 6, 2991-3018. [CrossRef]

7. Yue, P.; Li, Z.; Moult, J. Loss of protein structure stability as a major causative factor in monogenic disease. J. Mol. Biol. 2005, 353, 459-473. [CrossRef]

8. Stefl, S.; Nishi, H.; Petukh, M.; Panchenko, A.R.; Alexov, E. Molecular mechanisms of disease-causing missense mutations. J. Mol. Biol. 2013, 425, 3919-3936. [CrossRef]

9. Wang, R.; Hozumi, Y.; Yin, C.; Wei, G.-W. Mutations on COVID-19 diagnostic targets. Genomics. 2020, in press. [CrossRef]

10. Korber, B.; Fischer, W.M.; Gnanakaran, S.; Yoon, H.; Theiler, J.; Abfalterer, W.; Hengartner, N.; Giorgi, E.E.; Bhattacharya, T.; Foley, B.; et al. Tracking changes in SARS-CoV-2 Spike: Evidence that D614G increases infectivity of the COVID-19 virus. Cell 2020, 182, 812-827.e19. [CrossRef] 
11. Grubaugh, N.D.; Hanage, W.P.; Rasmussen, A.L. Making sense of mutation: What D614G means for the COVID-19 pandemic remains unclear. Cell 2020, 182, 794-795. [CrossRef] [PubMed]

12. Chen, J.; Wang, R.; Wang, M.; Wei, G.-W. Mutations strengthened SARS-CoV-2 infectivity. J. Mol. Biol. 2020, 432, 5212-5226. [CrossRef] [PubMed]

13. Bar-On, Y.M.; Flamholz, A.; Phillips, R.; Milo, R. Science Forum: SARS-CoV-2 (COVID-19) by the numbers. Elife 2020, 9, e57309. [CrossRef] [PubMed]

14. Wang, Y.; Sun, J.; Zhu, A.; Zhao, J.; Zhao, J. Current understanding of middle east respiratory syndrome coronavirus infection in human and animal models. J. Thorac. Dis. 2018, 10 (Suppl. 19), S2260. [CrossRef] [PubMed]

15. Sevajol, M.; Subissi, L.; Decroly, E.; Canard, B.; Imbert, I. Insights into RNA synthesis, capping, and proofreading mechanisms of SARS-coronavirus. Virus Res. 2014, 194, 90-99. [CrossRef] [PubMed]

16. Ferron, F.; Subissi, L.; De Morais, A.T.S.; Le, N.T.T.; Sevajol, M.; Gluais, L.; Decroly, E.; Vonrhein, C.; Bricogne, G.; Canard, B.; et al. Structural and molecular basis of mismatch correction and ribavirin excision from coronavirus rna. Proc. Natl. Acad. Sci. USA 2018, 115, E162-E171. [CrossRef]

17. Sanjuán, R.; Domingo-Calap, P. Mechanisms of viral mutation. Cell. Mol. Life Sci. 2016, 73, 4433-4448. [CrossRef]

18. Yin, C. Genotyping coronavirus SARS-CoV-2: Methods and implications. Genomics 2020, 112, 3588-3596. [CrossRef]

19. Phan, T. Genetic diversity and evolution of SARS-CoV-2. Infect. Genet. Evol. 2020, 81, 104260. [CrossRef]

20. Khan, K.A.; Cheung, P. Presence of mismatches between diagnostic PCR assays and coronavirus sars-cov-2 genome. R. Soc. Open Sci. 2020, 7, 200636. [CrossRef]

21. Wang, R.; Hozumi, Y.; Yin, C.; Wei, G.-W. Decoding SARS-CoV-2 transmission, evolution, and ramification on COVID-19 diagnosis, vaccine, and medicine. J. Chem. Inf. Model. 2020. [CrossRef]

22. Baum, A.; Fulton, B.O.; Wloga, E.; Copin, R.; Pascal, K.E.; Russo, V.; Giordano, S.; Lanza, K.; Negron, N.; $\mathrm{Ni}, \mathrm{M}$; ; et al. Antibody cocktail to SARS-CoV-2 spike protein prevents rapid mutational escape seen with individual antibodies. Science 2020, 369, 1014-1018. [CrossRef]

23. Di Giorgio, S.; Martignano, F.; Torcia, M.G.; Mattiuz, G.; Conticello, S.G. Evidence for RNA editing in the transcriptome of 2019 novel coronavirus. Sci. Adv. 2020, 6, eabb5813. [CrossRef] [PubMed]

24. Simmonds, P. Rampant C > U hypermutation in the genomes of SARS-CoV-2 and other coronaviruses: Causes and consequences for their short-and long-term evolutionary trajectories. Msphere 2020, 5. [CrossRef] [PubMed]

25. Matyášek, R.; Kovařík, A. Mutation patterns of human SARS-CoV-2 and Bat RaTG13 coronavirus genomes are strongly biased towards C > U transitions, indicating rapid evolution in their hosts. Genes 2020, 11, 761. [CrossRef]

26. Zheng, Y.-H.; Irwin, D.; Kurosu, T.; Tokunaga, K.; Sata, T.; Peterlin, B.M. Human APOBEC3F is another host factor that blocks human immunodeficiency virus type 1 replication. J. Virol. 2004, 78, 6073-6076. [CrossRef]

27. Nishikura, K. A-to-I editing of coding and non-coding RNAs by ADARs. Nat. Rev. Mol. Cell Biol. 2016, 17, 83-96. [CrossRef] [PubMed]

28. Smith, H.C.; Bennett, R.P.; Kizilyer, A.; McDougall, W.M.; Prohaska, K.M. Functions and regulation of the APOBEC family of proteins. In Seminars in Cell $\mathcal{E}$ Developmental Biology; Elsevier: Amsterdam, The Netherlands, 2012; Volume 23, pp. 258-268.

29. Liu, M.-C.; Liao, W.-Y.; Buckley, K.M.; Yang, S.Y.; Rast, J.P.; Fugmann, S.D. AID/APOBEC-like cytidine deaminases are ancient innate immune mediators in invertebrates. Nat. Commun. 2018, 9, 1-11. [CrossRef]

30. Samuel, C.E. Adenosine deaminases acting on RNA (ADARs) are both antiviral and proviral. Virology 2011, 411, 180-193. [CrossRef]

31. Gonzales-van Horn, S.R.; Sarnow, P. Making the mark: The role of adenosine modifications in the life cycle of RNA viruses. Cell Host Microbe 2017, 21, 661-669. [CrossRef]

32. Harris, R.S.; Dudley, J.P. APOBECs and virus restriction. Virology 2015, 479, 131-145. [CrossRef]

33. Song, P.; Li, W.; Xie, J.; Hou, Y.; You, C. Cytokine storm induced by SARS-CoV-2. Clin. Chim. Acta 2020, 509, 280-287. [CrossRef] [PubMed]

34. Shu, Y.; McCauley, J. Gisaid: Global initiative on sharing all influenza data-from vision to reality. Eurosurveillance 2017, 22, 30494. [CrossRef] [PubMed]

35. Sievers, F.; Higgins, D.G. Clustal omega. Curr. Protoc. Bioinform. 2014, 48, 3-13. [CrossRef] 
36. Söding, J. Protein homology detection by hmm-hmm comparison. Bioinformatics 2005, 21, 951-960. [CrossRef]

37. Blackshields, G.; Sievers, F.; Shi, W.; Wilm, A.; Higgins, D.G. Sequence embedding for fast construction of guide trees for multiple sequence alignment. Algorithms Mol. Biol. 2010, 5, 21. [CrossRef]

38. Cock, P.J.A.; Antao, T.; Chang, J.T.; Chapman, B.A.; Cox, C.J.; Dalke, A.; Friedberg, I.; Hamelryck, T.; Kauff, F.; Wilczynski, B.; et al. Biopython: Freely available python tools for computational molecular biology and bioinformatics. Bioinformatics 2009, 25, 1422-1423. [CrossRef] [PubMed]

39. Alexandrov, L.B.; Nik-Zainal, S.; Wedge, D.C.; Aparicio, S.A.J.R.; Behjati, S.; Biankin, A.V.; Bignell, G.R.; Bolli, N.; Borg, A.; Børresen-Dale, A.-L.; et al. Signatures of mutational processes in human cancer. Nature 2013, 500, 415-421. [CrossRef]

40. Hewagama, A.; Patel, D.; Yarlagadda, S.; Strickland, F.M.; Richardson, B.C. Stronger inflammatory/cytotoxic T-cell response in women identified by microarray analysis. Genes Immun. 2009, 10, 509-516. [CrossRef]

41. Klein, S.L. Sex influences immune responses to viruses, and efficacy of prophylaxis and treatments for viral diseases. Bioessays 2012, 34, 1050-1059. [CrossRef]

42. Roberts, S.A.; Lawrence, M.S.; Klimczak, L.J.; Grimm, S.A.; Fargo, D.; Stojanov, P.; Kiezun, A.; Kryukov, G.V.; Carter, S.L.; Saksena, G.; et al. An APOBEC cytidine deaminase mutagenesis pattern is widespread in human cancers. Nat. Genet. 2013, 45, 970-976. [CrossRef]

43. Lee, N.; Hui, D.; Wu, A.; Chan, P.; Cameron, P.; Joynt, G.M.; Ahuja, A.; Yung, M.Y.; Leung, C.B.; To, K.F.; et al. A major outbreak of severe acute respiratory syndrome in Hong Kong. N. Engl. J. Med. 2003, 348, 1986-1994. [CrossRef] [PubMed]

44. Drexler, J.F.; Gloza-Rausch, F.; Glende, J.; Corman, V.M.; Muth, D.; Goettsche, M.; Seebens, A.; Niedrig, M.; Pfefferle, S.; Yordanov, S.; et al. Genomic characterization of severe acute respiratory syndrome-related coronavirus in European bats and classification of coronaviruses based on partial RNA-dependent RNA polymerase gene sequences. J. Virol. 2010, 84, 11336-11349. [CrossRef] [PubMed]

45. Hu, D.; Zhu, C.; Ai, L.; He, T.; Wang, Y.; Ye, F.; Yang, L.; Ding, C.; Zhu, X.; Lv, R.; et al. Genomic characterization and infectivity of a novel SARS-like coronavirus in Chinese bats. Emerg. Microbes Infect. 2018, 7, 1-10. [CrossRef] [PubMed]

46. Zhou, P.; Yang, X.-L.; Wang, X.-G.; Hu, B.; Zhang, L.; Zhang, W.; Si, H.-R.; Zhu, Y.; Li, B.; Huang, C.-L.; et al. A pneumonia outbreak associated with a new coronavirus of probable bat origin. Nature 2020, 579, 270-273. [CrossRef] [PubMed]

47. Wu, F.; Wang, A.; Liu, M.; Wang, Q.; Chen, J.; Xia, S.; Ling, Y.; Zhang, Y.; Xun, J.; Lu, L.; et al. Neutralizing antibody responses to SARS-CoV-2 in a COVID-19 recovered patient cohort and their implications. medRxiv 2020. [CrossRef]

48. Bai, Y.; Yao, L.; Wei, T.; Tian, F.; Jin, D.-Y.; Chen, L.; Wang, M. Presumed asymptomatic carrier transmission of COVID-19. JAMA 2020, 323, 1406-1407. [CrossRef]

(C) 2020 by the authors. Licensee MDPI, Basel, Switzerland. This article is an open access article distributed under the terms and conditions of the Creative Commons Attribution (CC BY) license (http://creativecommons.org/licenses/by/4.0/). 